\title{
SISTEM PENGAMBLAN KEPUTUSAN PEMILIHAN BIBIT JAGUNG DENGAN METODE ANALYTICAL HIERARCHY PROCESS (AHP) PADA TOKO ABADI JAYA LAMPUNG TIMUR
}

\author{
Ferly ardhy ${ }^{1}$, Supriyanto ${ }^{2}$, Afif Zakhulan ${ }^{3}$ \\ Program studi Sistem Informasi ${ }^{123}$ \\ STMIK Dian Cipta Cendikia Kotabumi \\ $\mathrm{J} 1$ negara no .03 candimas kotabumi, lampung utara \\ ferly@dcc.ac.id,supriyanto@dcc.ac.id,afif@gmail.com
}

\begin{abstract}
Abstrak
Bibit Jagung merupakan Tanaman komoditi yang sangat populer ditanam oleh petani khusunya indonesia dikarenakan banyak yang menggunakan tanaman ini selain banyak manfaatnya juga merupakan tanaman pangan. Pengguna biasanya kesulitan memilih Bibit Jagung yang ingin dibeli karena banyaknya jenis Bibit Jagung, kontruksi tanah, dan harga. Sehingga dibutuhkan sistem pendukung keputusan yang dapat membantu pengguna menentukan Bibit Jagung sesuai alternatif dan kriteria yang diinginkan
\end{abstract}

Dalam penelitian ini, metode yang digunakan adalah Analitycal Hierarchy Process (AHP), Metode pengembangan sistem dibuat dengan menggunakan metode Prototyping dengan menggunakan alat pengembangan sistem Unified Modelling Language (UML) yang terdiri dari Use Case, Activity Diagram, Sequence Diagram, dan Class Diagram serta menggunakan bahasa pemrograman PHP dan menggunakan database MySql.

Metode ini digunakan karena mampu memilih alternatif terbaik sehingga menghasilkan keputusan yang optimal sesuai dengan spesifikasi dan dana yang dimiliki pengguna.

Kata kunci : komoditi, petani, sistem pendukung keputusan, database 
Abstrac

Corn Seed is a very popular commodity crop planted by farmers especially Indonesia because many who use this plant besides many benefits it is also a panga plant. Users usually have difficulty choosing corn seeds that they want to buy because of the many types of corn seeds, soil construction, and prices. So that a decision support system is needed that can help users determine Corn Seed according to the alternatives and desired criteria

In this study, the method used is the Analitycal Hierarchy Process (AHP), System development methods are made using the Prototyping method using a Unified Modeling Language (UML) system development tool consisting of Use Case, Activity Diagram, Sequence Diagram, and Class Diagram and using the PHP programming language and using the MySql database.

This method is used because it is able to choose the best alternative so as to produce optimal decisions in accordance with the specifications and funds owned by the user.

Keywords: commodity, farmer, decision support system, database 


\section{Latar Belakang}

Pemilihan bibit jagung yang tepat merupakan salah satu aspek yang perlu diperhatikan oleh petani (dalam hal ini pengambil keputusan) sebelum melakukan pembelian. Penelitian mengenai sistem pendukung keputusan dalam pemilihan bibit jagung sudah pernah dilakukan. Penelitian tersebut menggunakan metode yaitu Analytical Hierarchy Process (AHP Metode AHP digunakan untuk menentukan bobot kepentingan Hasil dari penelitian tersebut adalah sistem yang dibangun mampu memberikan perangkingan bibit jagung terbaik yang sesuai dengan kriteria yang dipilih oleh petani [1]

\section{Kajian Pustaka}

2.1 Sistem

Menurut Sutarbi menyebutkan bahwa :

"Sistem adalah suatu kesatuan yang terdiri atas komponen atau elemen yang saling berinteraksi, saling terkait atau saling bergantung membentuk keseluruhan satuan yang kompleks. Sistem juga merupakan gagasan yang terorganisir dan saling terikat satu sama lain untuk tujuan klasifikasi atau analisis yang terjalin karena adanya kondisi harmonis, terinteraksi dan teratur. Secara umum pengertian sistem adalah kesatuan object/benda yang memiliki hubungan diantara komponen itu” [2]

\subsection{Informasi}

Menurut Sutarbi menyebutkan bahwa :

"Informasi adalah data yang diolah sehingga dapat dijadikan dasar untuk mengambil keputusan, Secara umum informasi dapat di definisikan sebagai hasil dari pengolahan data dalam suatu bentuk yang berguna dan berarti bagi penerimanya yang menggambarkan suatu kejadian-kejadian yang nyata yang digunakan untuk mengambil keputusan" [2]

\subsection{Bahasa Pemrograman}

Menurut Nugroho menyatakan bahwa :

"PHP (Hipertext Preprocessor) adalah sebuah bahasa pemograman yang berbentuk scripting, sistem kerja dari program ini adalah sebagai interpreteur bukan sebagai compiler" [3].

\subsection{Metode Pengembangan sistem}

AHP sangat cocok dan flexibel digunakan untuk menentukan keputusan yang menolong seorang decision maker untuk mengambil keputusan yang kualitatif dan kuantitatif berdasarkan segala aspek yang dimilikinya . Kelebihan lain dari AHP adalah dapat memberikan gambaran yang jelas dan rasional kepada decision maker tentang keputusan yang dihasilkan [4]

\subsection{Alat Pengembangan Sistem}

\section{Unified Modelling Language (UML)}

Menurut Munawar (2005 : 17) UML [5](Unified Modelling Language) adalah alat bantu yang menyediakan bahasa pemodelan visual yang memungkinkan bagi pengembang sistem untuk membuat cetak biru atas visi mereka dalam bentuk yang baku, mudah dimengerti serta dilengkapi dengan mekanisme yang efektif untuk berbagi (sharing) dan mengkomunikasikan rancangan mereka dengan yang lain

\section{Jenis Penelitian}

Jenis penelitian ini adalah penelitian deskriptif, yaitu metode yang menggambarkan suatu keadaan atau permasalahan yang sedang terjadi berdasarkan fakta dan data-data yang diperoleh dan dikumpulkan pada waktu melaksanakan penelitian. Sistem informasi yang dibangun pada penelitian ini menerapkan Computing Approach yakni mengimplementasikan metode $A H P$ pada SPK Pemilihan Bibit jagung berbasis web

\section{Metode Pengembangan Sistem}

\section{Tahap 1 : Planning}

Sistem yang sedang berjalan

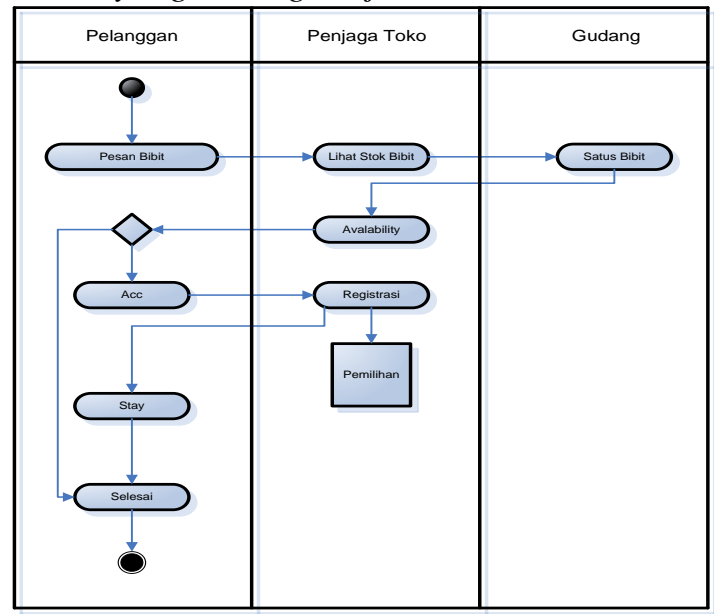

Gambar1. Masalah Sistem sedang berjalan 
Tahap 2 : Analisis

Sesuai dengan metode penelitian, metode analisis data yang digunakan oleh penulis dalam penelitian ini adalah menggunakan analisis data kualitatif. Analisis data kualitatif ini adalah analisis terhadap data yang diperoleh berdasarkan kemampuan nalar peneliti dalam menghubungkan fakta-fakta, data dan informasi. Jadi metode analisis data kualitatif yaitu dengan menyajikan hasil wawancara dan melakukan analisis terhadap masalah yang ditemukan di lapangan sehingga akan diperoleh gambaran yang jelas tentang objek yang diteliti dan kemudian akan ditarik kesimpulan.

Adapun Untuk usulan sistem akan digambarkan pada usecase berikut :

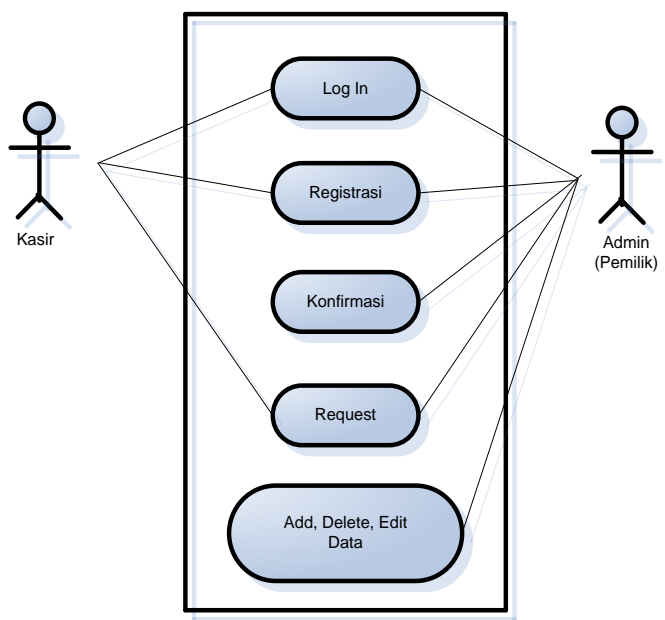

Gambar 2 Usecase Diagram

\section{Tahap 3 : Desaign}

Adapun Tahap Desaign akan berisi Rancangan masukan dan rancangan keluaran dari sistem :

\section{Rancangan Masukan}

Tampilan Menu Utama Sistem

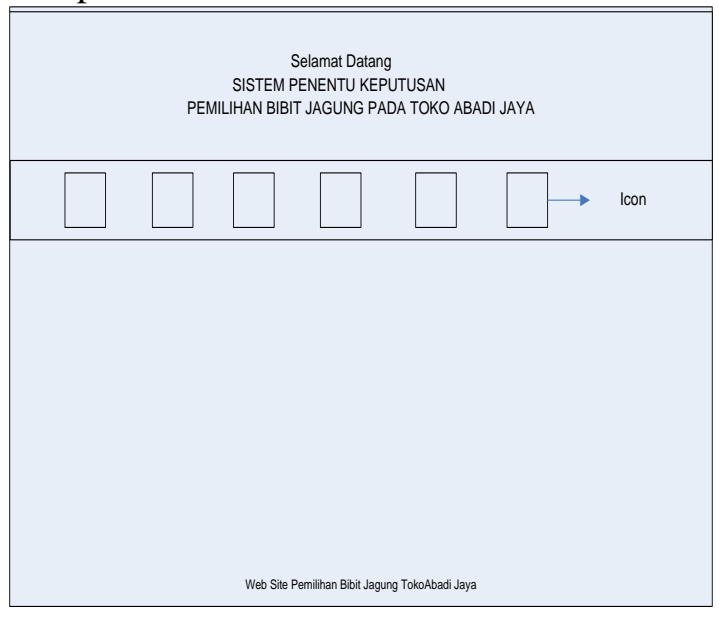

Gambar 3 Menu Utama

Tampilan Login (Input Username dan Password)

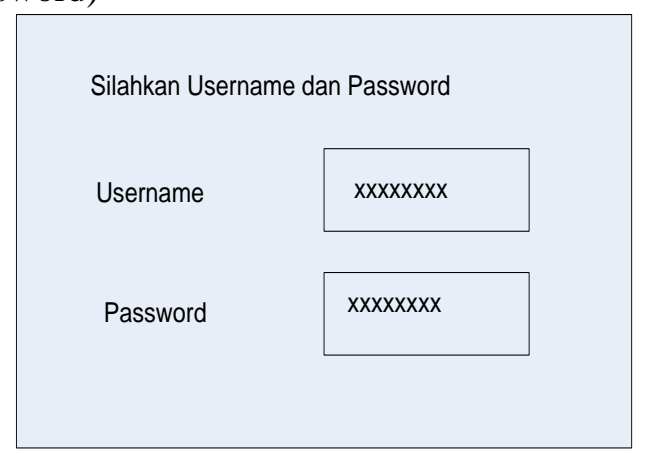

Gambar 4 Login

\section{Tahap 4 : Pengkodean / Implementasi}

Adapun pengkodean yang penulis gunakan adalah :

a) Nomor Bibit Jagung

b) Kode Hasil

\section{Tahap 5 : Testing Software}

Pada pengujian sistem ini, penulis memakai metode $A H P$ sebagai sarana penguji dalam menguji sistem yang telah dibuat. Pengujian dengan menggunakan metode AHP ini merupakan metode pengujian yang berfokus pada persyaratan fungsional perangkat lunak yang dibuat. Contoh pengujian metode $A H P$ pada table di bawah ini :

Tabel 1 Pengujian Fungsional Sistem

\begin{tabular}{|c|c|c|c|c|}
\hline $\begin{array}{l}\mathbf{N} \\
\mathbf{0}\end{array}$ & $\begin{array}{l}\text { Kode } \\
\text { Opera } \\
\text { si }\end{array}$ & Kondisi & $\begin{array}{l}\text { Respo } \\
\text { n } \\
\text { Sistem }\end{array}$ & $\begin{array}{l}\text { Hasi } \\
1\end{array}$ \\
\hline 1 & $\begin{array}{l}01 \\
\text { Login }\end{array}$ & 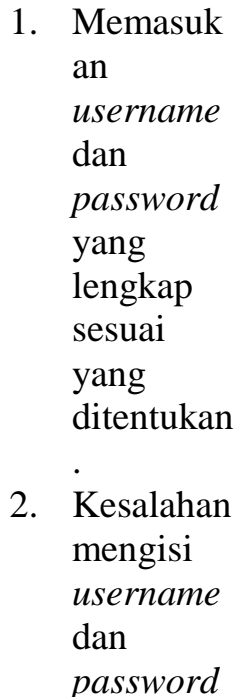 & ? & ? \\
\hline
\end{tabular}




\begin{tabular}{|c|c|c|c|c|}
\hline 2 & $\begin{array}{l}02 \\
\text { Search } \\
\text { Data }\end{array}$ & 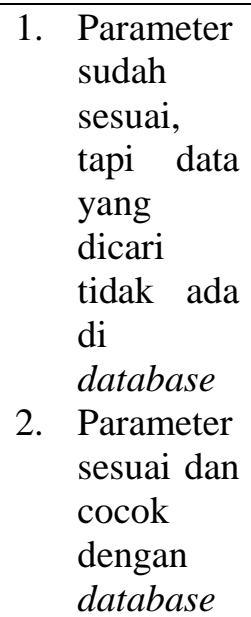 & ? & ? \\
\hline 3 & $\begin{array}{l}03 \\
\text { Add } \\
\text { Data }\end{array}$ & $\begin{array}{l}\text { 1. Data yang } \\
\text { dimasuka } \\
\mathrm{n} \text { lengkap } \\
\text { 2. } \begin{array}{l}\text { Duplicate } \\
\text { primary } \\
\text { key }\end{array} \\
\end{array}$ & ? & ? \\
\hline 4 & $\begin{array}{l}04 \\
\text { Delete } \\
\text { Data }\end{array}$ & 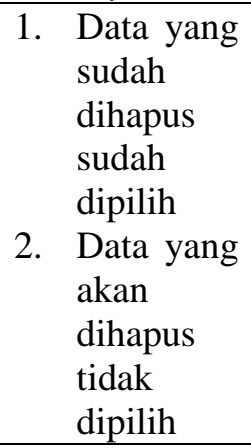 & ? & ? \\
\hline 5 & $\begin{array}{l}05 \\
\text { Edit } \\
\text { Data }\end{array}$ & $\begin{array}{ll}\text { 1. } & \text { Mengisi } \\
\text { data } \\
\text { perubahan } \\
\text { pada } \\
\text { textbox } \\
\text { dengan } \\
\text { lengkap } \\
\text { 2. } \begin{array}{l}\text { Duplicate } \\
\text { primary } \\
\text { key }\end{array} \\
\end{array}$ & ? & ? \\
\hline 6 & $\begin{array}{l}06 \\
\text { Hitung } \\
\text { Rumus } \\
\text { AHP }\end{array}$ & $\begin{array}{l}\text { 1. Perhitung } \\
\text { an rumus } \\
\text { AHP }\end{array}$ & ? & ? \\
\hline
\end{tabular}

\section{Tahap 6 : Delivery Software}

Setelah software yang sudah dilakukan pengujian dengan metode $A H P$ dan lulus pengujian, maka software akan diserahkan kepada pelanggan untuk mendapatkan feedback atau umpan balik berupa komentar atau keluhan dari software yang dibuat. Dan setelah dari proses feedback ini maka akan kembali ke proses komunikasi.

\section{Adapun kelemahan dari sistem tersebut adalah:}

Sering terjadi kekeliruan dalam Penentuan bibit jagung yang sesuai dengan $\mathrm{PH}$ tanah sehingga hasil panen kurang maksimal. Sulit dalam hal penentuan bibit jagung yang sesuai dengan $\mathrm{PH}$ tanah. Arsip-arsip atau referensi dari kasus yang sama sering hilang dikarenakan belum menggunakan sistem

\section{Penentuan Kriteria}

Tabel 2. Penentuan kriteria pemilihan bibit jangung

\begin{tabular}{|c|c|c|}
\hline No. Kriteria & Kriteria & $\begin{array}{l}\text { Sub } \\
\text { Kriteria }\end{array}$ \\
\hline \multirow{3}{*}{1} & \multirow{3}{*}{$\mathrm{Ph}$ Tanah } & 5 \\
\hline & & 6 \\
\hline & & 7 \\
\hline \multirow{3}{*}{2} & \multirow{3}{*}{ Suhu } & 20 derajat \\
\hline & & 25 derajat \\
\hline & & 30 derajat \\
\hline \multirow{3}{*}{3} & \multirow{3}{*}{ Cahaya } & Kurang \\
\hline & & Cukup \\
\hline & & Lebih \\
\hline
\end{tabular}

6. Membuat bagan AHP

Berikut adalah bagan kriteria dari Penetuan kriteria

Sasaran

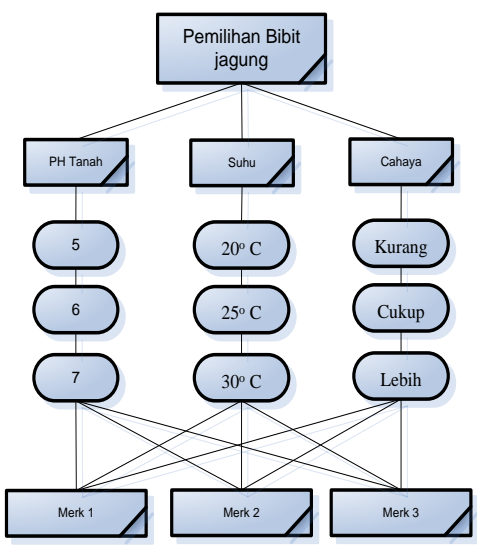

Alternatif

Gambar 5 Bagan Kriteria 
Adapun Untuk usulan sistem akan digambarkan pada usecase berikut :

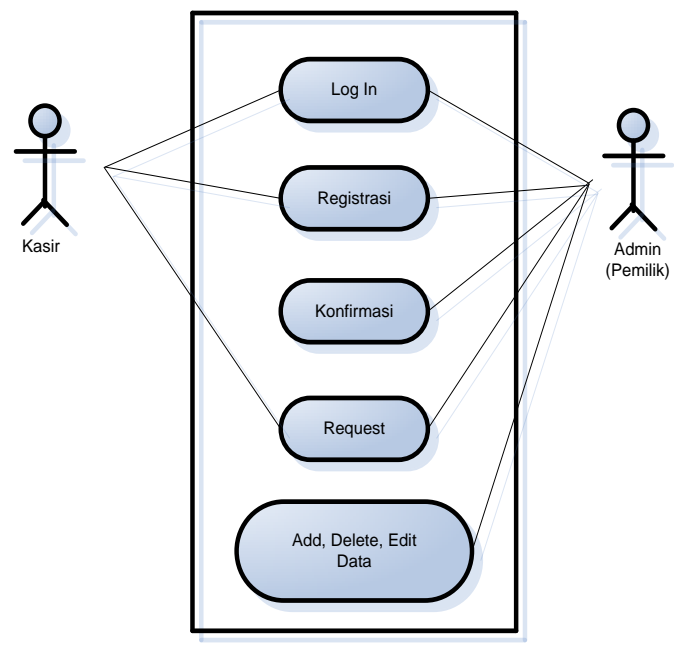

Gambar 6 Usecase Diagram

Untuk Usecase Diagram Activity yang lebih detail bisa dilihat dibawah ini :

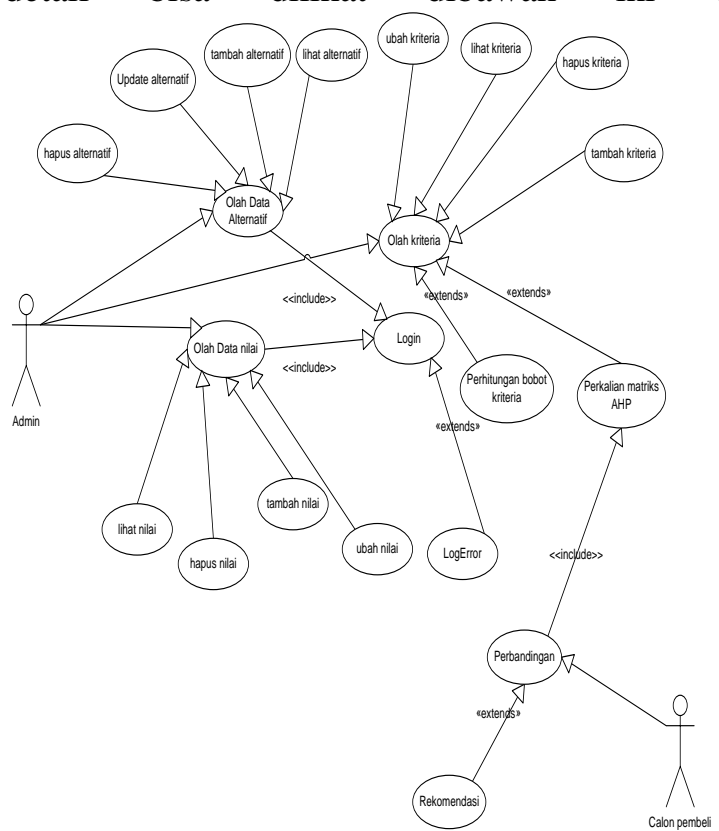

Gambar 7 Use Case Sistem Pengambilan Keputusan Bibit Jagung

\section{Hasil Program}

1 Tampilan Form Password
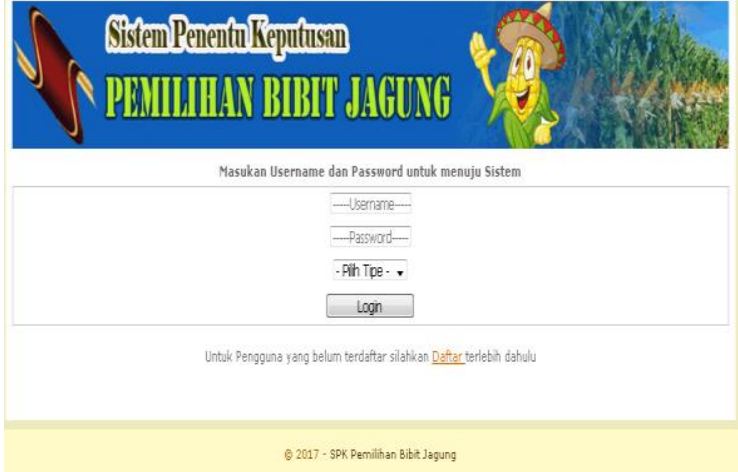

Gambar 8 Tampilan Form Password

2. Tampilan Registrasi Pengguna "Form Daftar"

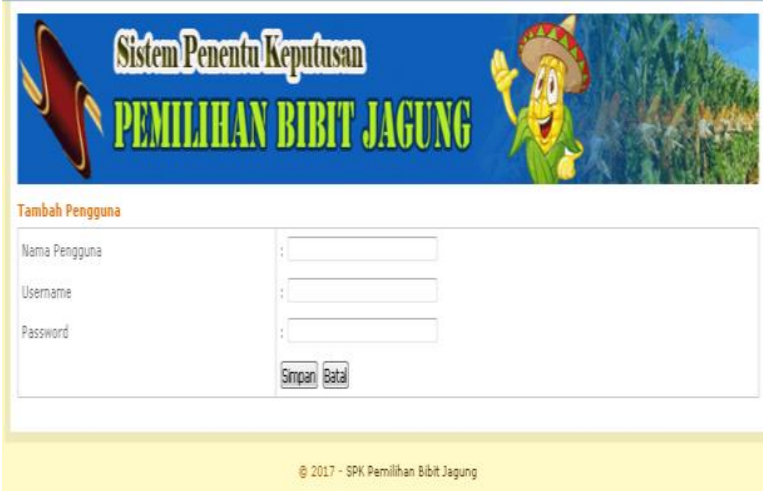

Gambar 9 Tampilan Registrasi Pengguna

3. Tampilan Form Menu Utama Admin

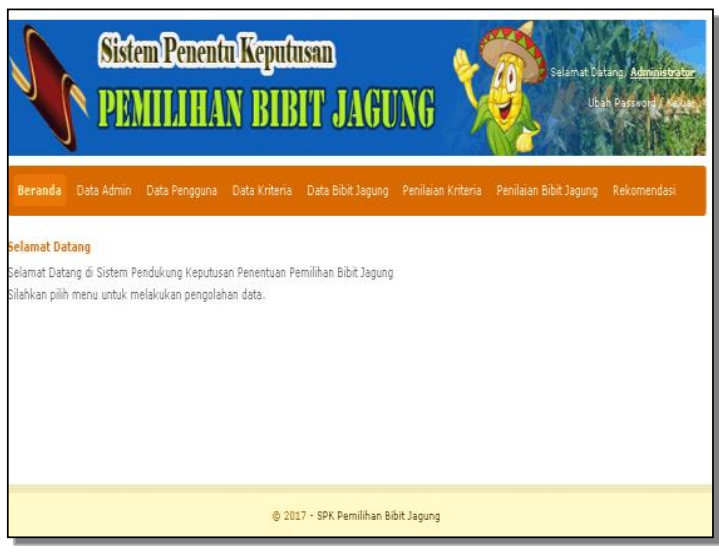

Gambar 10 Tampilan Form Menu Utama Admin

4. Tampilan Form Data Admin 


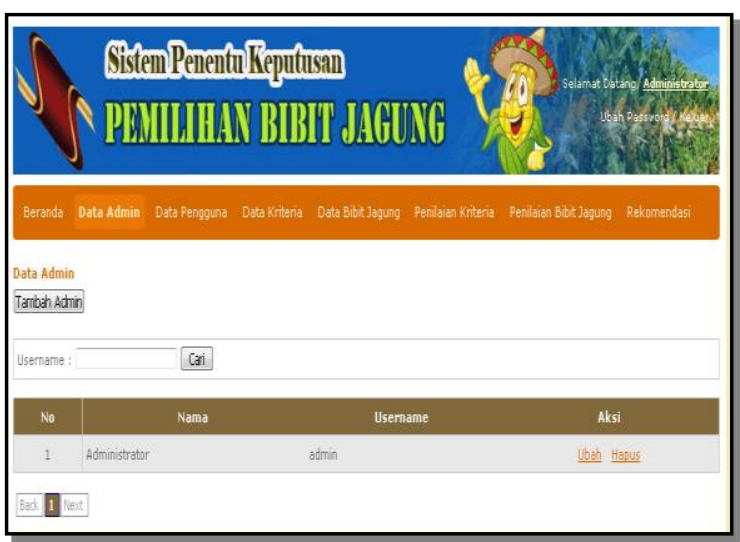

Gambar 11 Tampilan Data Admin

5. Tampilan Form Data Pengguna

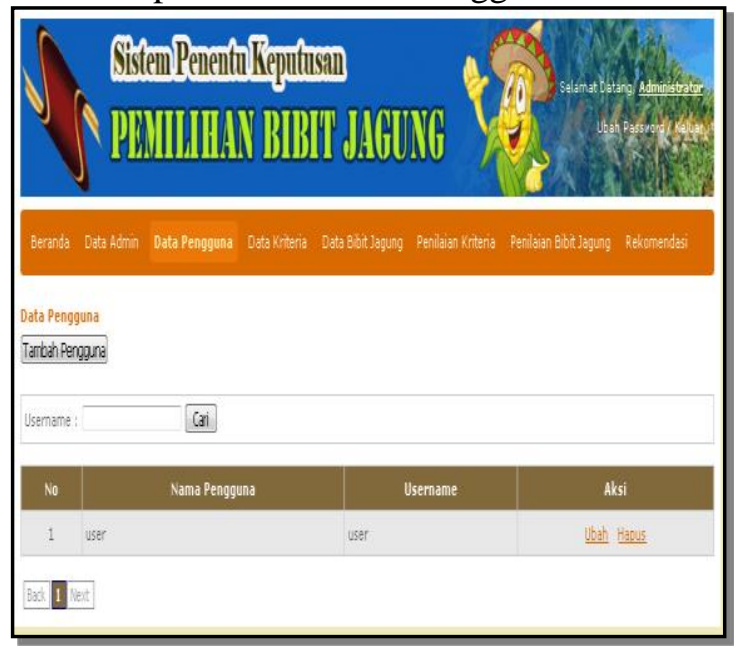

Gambar 12 Tampilan Form Data Pengguna

6. Tampilan Data Kriteria

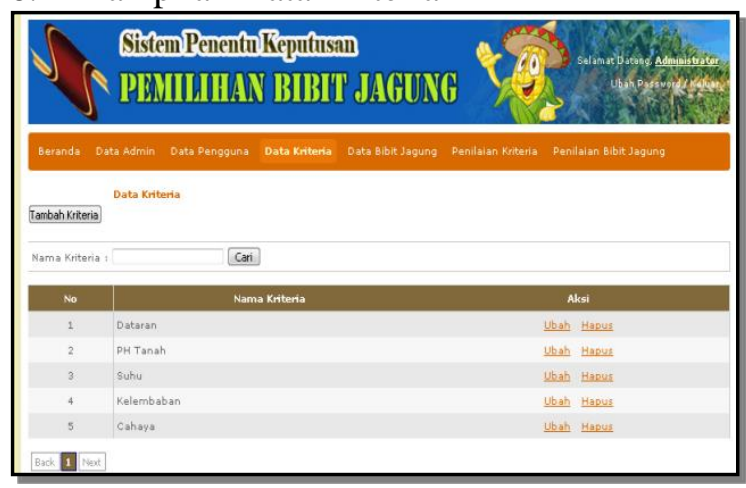

Gambar 13Tampilan Form Data Pengguna

7. Tampilan Data Bibit Jagung

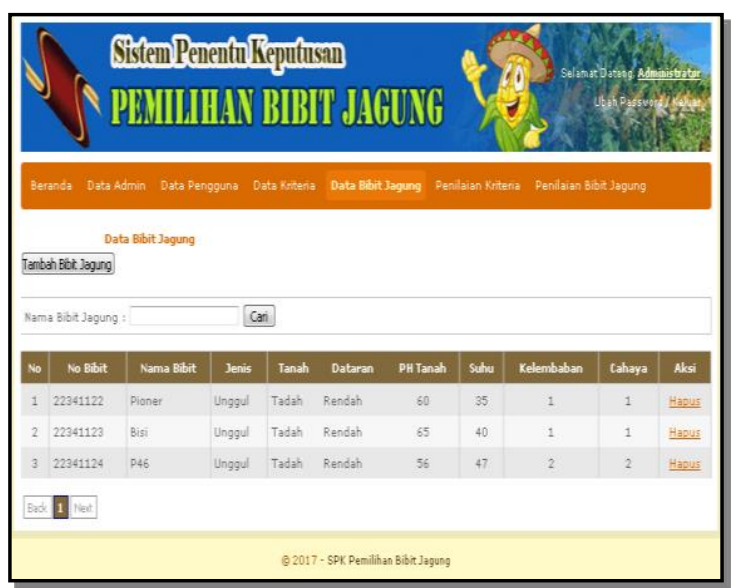

Gambar 14 Tampilan Form Data Bibit Jagung

8. Penilaian Kriteria

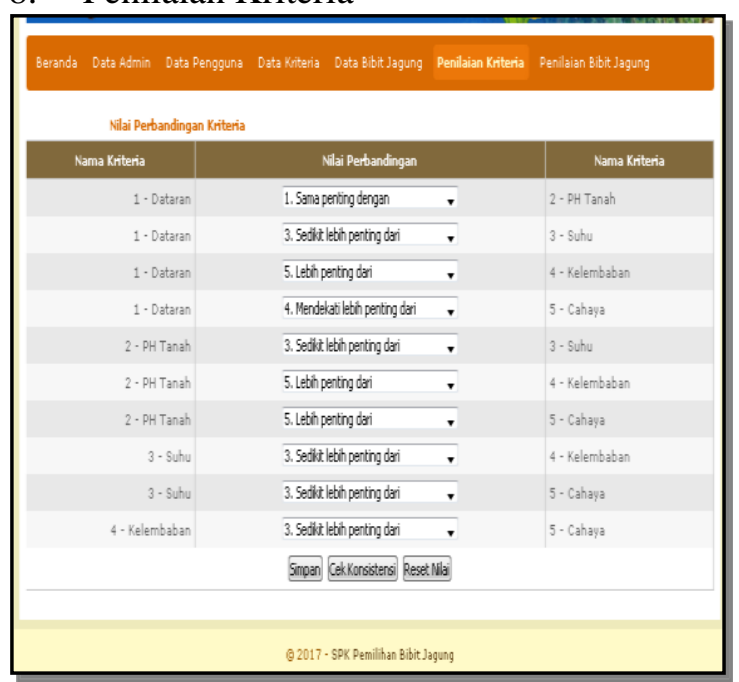

Gambar 15 Tampilan Penilaian Kriteria

9. Penilaian Pemilihan Bibit Jagung

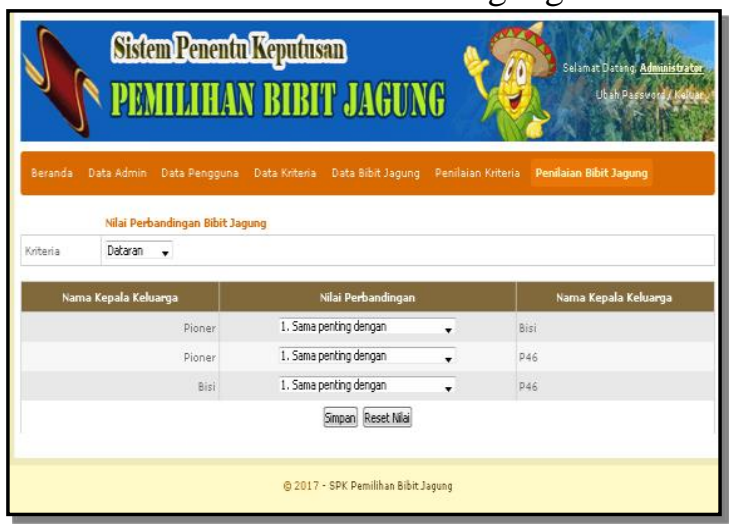

Gambar 16 Tampilan Pemilihan Bibit Jagun 10. Rekomendasi 


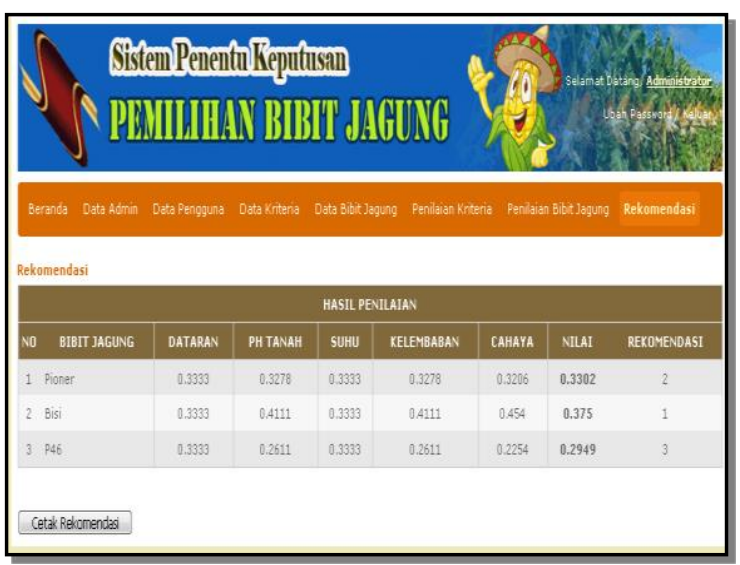

Gambar 17 Tampilan Rekomendasi

\section{PENUTUP}

Setelah penulis mengadakan penelitian Sistem Pengambilan Keputusan Pemilihan Bibit Jagung pada Toko Abadi Jaya dapat mengambil kesimpulan bahwa :

1. Pengolahan data yang masih menggunakan cara konvensional yaitu secara manual, sehingga menghasilkan data yang kurang akurat dan terjadi keterlambatan dalam proses kerja.

2. Dengan menggunakan SPK Pemilihan Bibit Jagung maka diharapkan agar dapat membantu proses pengolahan data secara efektif dan efisien.

3. Lebih membantu petani dalam memilih bibit jagung yang sesuai sehingga meningkatkan hasil panen.

\section{DAFTAR PUSTAKA}

[1] Kusumadewi, Sri, Et Al. "Fuzzy MultiAttribute Decision Making (Fuzzy Madm)." Yogyakarta: Graha Ilmu (2006): 78-79.
[2] Sutabri, Tata. "Sarjana Komputer di Era Informasi." (2007).

[3] Hapsari, Irma Dewi, Nugroho Sumarjiyanto, and Evi Yulia Purwanti. "Perencanaan dan Penganggaran Kampus Berkelanjutan: Green Campus Universitas Diponegoro." Teknik35.2 (2014): 8693.

[4] Parida, Merri, And Achmad Benny Mutiara. "Sistem Pendukung Keputusan Penentuan Penilaian Karyawan Berprestasi Menggunakan Metode Saw Dan Ahp." Jurnal Informasi Dan Komputer 4.2 (2016).

[5] Munawar, Ahmad. "Pemodelan Visual Dengan Uml." Jakarta: Graha Ilmu (2005). 